\title{
Alectinib (Alecensa)-induced reversible grade IV nephrotoxicity: a case report and review of the literature
}

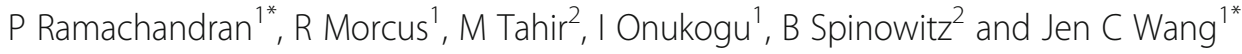

\begin{abstract}
Background: Lung cancer is among the top causes of cancer-related mortality in men and is the second most common cancer after breast cancer in women. There are approximately 234,030 new cases of lung cancer and 154,050 deaths from lung cancer in 2018 as per the latest American Cancer Society's report. Alectinib, a more potent orally active tyrosine kinase inhibitor which was approved by the US Food \& Drug Administration for anaplastic lymphoma kinase-positive lung adenocarcinoma, has been shown to have a reasonable safety profile when compared with other anaplastic lymphoma kinase-targeted therapy. As per research studies, grade 1 or 2 renal impairment has been reported but grade 4 renal toxicity due to alectinib has not been reported so far. We report a case of acute renal failure caused by alectinib which necessitated emergency dialysis. This is the first case report describing the severe renal toxicity of alectinib.
\end{abstract}

Case presentation: We describe a case of 72-year-old Taiwanese man diagnosed with stage IV anaplastic lymphoma kinase-positive adenocarcinoma of the lung initially treated with crizotinib for over a year, which was switched to alectinib due to disease progression with brain metastasis. Within 6 weeks of starting alectinib, he developed acute renal failure needing emergency dialysis support. His renal failure was secondary to acute tubular necrosis and had a complete reversal within 7-10 days on withdrawing the medication. When he was re-challenged with alectinib, his creatinine started to worsen again which confirmed the renal toxicity of alectinib.

Conclusions: This case emphasizes the uncommon adverse effect of the anaplastic lymphoma kinase-targeted therapy alectinib causing acute renal failure manifesting as acute tubular necrosis. Recognition of alectinib nephropathy requires a thorough drug history and knowledge of risk factors that lessen its margin of safety at therapeutic ingestions. Frequent monitoring of renal functions and early nephrology referral significantly reduce the mortality and morbidity of these patients.

Keywords: Acute renal failure, Alectinib, Adenocarcinoma, ALK rearrangement, Acute tubular necrosis, Non-small cell lung cancer, Case report

\section{Background}

Alectinib-induced acute renal failure (ARF) is a very entity and has not been reported so far in the literature. The two major research trials carried out to assess the safety of alectinib mostly reported only grade 1 and 2 renal impairment. ARF needing emergency dialysis support has not been reported so far.

Non-small cell lung cancer (NSCLC) accounts for approximately $85 \%$ of all lung cancers. Histological classification of

\footnotetext{
* Correspondence: drpreethiram@hotmail.com; jcwang0005@gmail.com ${ }^{1}$ Division of Hematology/Oncology, Brookdale University Hospital Medical Center, Brooklyn, NY 11212, USA

Full list of author information is available at the end of the article
}

NSCLC includes adenocarcinoma, squamous cell carcinoma (SCC), and large cell carcinoma. The most common subtype of NSCLC is adenocarcinoma which has targetable genomic changes. The tyrosine kinase receptors involved in the translocations of adenocarcinoma include anaplastic lymphoma kinase (ALK) (2p23), ROS1 (6q22), and RET (10q11). These genomic translocations are most commonly seen in adenocarcinomas but can also be sometimes seen with squamous or adenosquamous variants. EML4/ALK is the most common ALK fusion found in lung adenocarcinoma (4 to $7 \%$ of cases) while $K I F 5 B / A L K$ is the second common in frequency (0.5\%) [1]. ROS1 fusions and RET fusion genomics can exist in a small percentage of patients with NSCLC. Alectinib is a 
targeted therapy used in treating ALK-positive adenocarcinoma. It is a more potent second-generation inhibitor of ALK which was given an accelerated approval by the United States Food \& Drug Administration (US FDA) in December 2015 for those who progressed on or are intolerant to crizotinib [2-4]. Alectinib was found to have more efficacy than crizotinib in the first-line setting in ALK-positive lung carcinoma. The most common adverse drug reactions with alectinib are weight gain (9.9\%), photosensitivity reaction $(5.3 \%)$, stomatitis $(3.3 \%)$, interstitial lung disease $(1.3 \%)$, and drug-induced liver injury (1.3\%). Severe renal impairment is a very rare adverse effect and has been so far reported in $<1 \%$ of the cases. This case is unusual because it is the first case to report the reversible nephrotoxicity of Alecensa (alectinib) in a patient needing hemodialysis support. This is a very important clinical concern in metastatic lung cancer as it increases the morbidity and mortality of these patients and monitoring for these side effects is needed to achieve good outcomes.

\section{Case presentation}

This is a case of a 72-year-old Taiwanese man who was diagnosed as having metastatic adenocarcinoma of the lung complicated by malignant right pleural effusion 2 years ago. He initially presented with weight loss, worsening cough, and worsening exertional shortness of breath for 3 months prior to presentation. He had a past medical history of type 2 diabetes mellitus, which was well controlled on insulin. He was an ex-smoker of tobacco with a tobacco smoking history of one pack a day for 10 years but he quit smoking tobacco 20 years ago. He also had a family history of non-Hodgkin lymphoma in his brother and breast cancer in his niece. He is retired and lives with his wife.

On examination, he was afebrile with heart rate of 70 beats/minute and with blood pressure (BP) of 130/ $80 \mathrm{mmHg}$. He appeared moderately built and was not in any respiratory distress. His respiratory examination was significant for dullness over the right middle and lower chest on percussion and was associated with reduced breath sounds on auscultation. His cardiovascular, abdominal, and neurological examinations were non-contributory.

His initial computed tomography (CT) scans demonstrated a middle lobe mass in his right lung and right lung pleural effusion. A positron emission tomography (PET) scan showed an increased uptake in the middle lobe mass in his right lung, subcarinal lymph nodes, several bilateral subcentimeter pulmonary nodules, and diffuse osseous metastasis. There was no evidence of brain metastasis as evidenced by magnetic resonance imaging (MRI) of his brain. He then had thoracentesis and pleural biopsy with the placement of a pleural catheter. The pleural biopsy was consistent with adenocarcinoma with an acinar pattern. Immunohistochemistry of the tumor cells was positive for cytokeratin (CK) 7, thyroid transcription factor 1 (TTF-1), and negative for CK20. A fluorescence in situ hybridization (FISH) showed evidence of ALK mutation (33\% of cells positive for rearrangement). His final diagnosis was stage IV ALK + adenocarcinoma of the lung with metastasis to pleura, mediastinum, and bones. Before the information of ALK positivity was obtained, he was started on combination chemotherapy consisting of carboplatin, Alimta (pemetrexed), and Avastin (bevacizumab) of which he successfully completed five cycles. He was followed up regularly in the clinic every 4 weeks. He tolerated the chemotherapy and had a good response with $30 \%$ reduction in the lung mass size. He was later started on crizotinib $250 \mathrm{mg}$ twice per day and had a significant response with improved tumor burden in his metastatic sites. He followed up in the clinic every 4 weeks initially for 6 months and then every 8 weeks for 1 year. During his follow-up visits, he remained stable with no evidence of disease progression. He remained on crizotinib for over a year and tolerated it well. During one of the follow-up clinic visits at around 18 months after diagnosis, an MRI scan of his brain was arranged due to a new symptom of headache; it showed numerous brain metastases which was consistent with progression of his disease. A decision was made to stop crizotinib and to start alectinib $600 \mathrm{mg}$ twice daily coupled with cranial radiation.

Within 5 weeks of starting alectinib, he developed ARF with his creatinine $(\mathrm{Cr})$ increasing up to $8.16 \mathrm{mg} / \mathrm{dL}$ and blood urea nitrogen (BUN) to $113 \mathrm{mg} / \mathrm{dl}$. He was anuric at presentation and his laboratory tests were consistent with hyperkalemia and acidosis with a potassium level of $7.1 \mathrm{mEq} / \mathrm{L}$ and bicarbonate $\left(\mathrm{HCO}_{3}\right)$ of $<9 \mathrm{mmol} / \mathrm{L}$. His renal workup revealed $\mathrm{BUN} / \mathrm{Cr}$ ratio of 13 , fractional excretion of sodium (FENa) of $16 \%$, urine sodium of > $83 \mathrm{mEq} / \mathrm{L}$, and urine osmolality of $334 \mathrm{mOsm} / \mathrm{kg}$. His renal ultrasound did not show any evidence for obstruction (hydronephrosis). Table 1 illustrates the laboratory values and Fig. 1 illustrates the timeline of our patient's renal functions.

Since he was refractory to medical treatment, he required continuous venovenous hemodialysis $(\mathrm{CVVH})$ due to the electrolyte imbalance. Alectinib was held on admission and dialysis was continued for 2 days until the electrolyte

Table 1 Laboratory values during alectinib therapy

\begin{tabular}{llll}
\hline & Baseline & $\begin{array}{l}\text { After starting } \\
\text { alectinib }\end{array}$ & $\begin{array}{l}1 \text { week upon } \\
\text { stopping alectinib }\end{array}$ \\
\hline Creatinine $(\mathrm{mg} / \mathrm{dl})$ & 1.0 & 8.16 & 1.75 \\
$\mathrm{BUN}(\mathrm{mg} / \mathrm{dl})$ & 15 & 113 & 23 \\
Potassium $(\mathrm{mEq} / \mathrm{L})$ & 4.1 & 7.1 & 4.3 \\
$\mathrm{HCO}_{3}(\mathrm{mmol} / \mathrm{L})$ & 24 & 8 & 24 \\
eGFR & 71 & 9 & 50
\end{tabular}

$B U N$ blood urea nitrogen, eGFR estimated glomerular filtration rate, $\mathrm{HCO}_{3}$ bicarbonate 
imbalance was corrected. Renal biopsy could not be performed as our patient refused.

His renal functions slowly recovered and $\mathrm{Cr}$ improved to $1.75 \mathrm{mg} / \mathrm{dL}$ within 2 days. He was re-challenged with alectinib at the same dose 24 hours after renal recovery. However, the medication had to be stopped again as his $\mathrm{Cr}$ started to worsen and rose to $3.6 \mathrm{mg} / \mathrm{dL}$ within 2 days of restarting alectinib. Currently, he is being treated with ceritinib, and his renal status has been stable with $\mathrm{Cr}$ levels ranging between 2 and $3 \mathrm{mg} / \mathrm{dL}$. He also has no progression of his metastatic disease as evidenced by his recent imaging.

\section{Discussion}

This case illustrates the sequence of renal impairment in a patient who was newly started on alectinib. It describes the acute rise in $\mathrm{Cr}$ within a few days of starting the medication which needed hemodialysis support to reverse the renal dysfunction. This case emphasizes the need for frequent monitoring of renal functions and avoiding other nephrotoxic drugs when using ALK inhibitors concomitantly.

Alectinib is an orally administered tyrosine kinase inhibitor which specifically targets $A L K$ and RET gene rearrangements [5] The initial approval in 2015 by the US FDA was for treating patients with ALK cancers for both locally advanced and metastatic NSCLCs who had disease progression on crizotinib [3, 4]. The response rate has been very good when used as a first-line therapy accounting for approximately $93.5 \%$. The median progression-free survival was shown to be 25.7 months when compared to 10.4 months with crizotinib. The incidence of brain metastasis was also shown to be lower when compared to crizotinib (9\% versus 41\%) [6]. Among the other therapies used in the treatment of ALK-positive NSCLC, alectinib has a reasonable safety profile, although the lack of controlled safety data limits this assessment. The common adverse reactions reported with alectinib include fatigue (41\%), myalgia (29\%) constipation (34\%), and edema (30\%). Serious side effects include interstitial lung disease, bradycardia, hepatotoxicity, and creatine phosphokinase (CPK) elevation.

The safety of alectinib was evaluated in 253 patients with ALK-positive NSCLC in two clinical trials: NP28761 and NP28673 [7]. The dose of $600 \mathrm{mg}$ twice a day was used, and the median duration of exposure was 9.3 months. According to these trials, the genitourinary adverse effects accounted for $<6 \%$ of all side effects and included hematuria, nocturia, dysuria, proteinuria, urinary retention, urinary incontinence, azotemia, and an increase in Cr. Most of these events were grade 1 and 2 in severity, with grade $\geq 3$ event (increased $\mathrm{Cr}$ ) reported in only one patient $(0.4 \%)$, where alectinib was discontinued [8]: Studies about alectinib-induced renal toxicity are very limited. Dose reduction and treatment breaks overcome the adverse renal effects of ALK inhibitors providing clinical benefits for patients.

To the best of our knowledge, our current case report is the first one to describe the ARF and the clinical course of renal impairment encountered with alectinib. Although the exact mechanism of ARF with alectinib is not clear so far, there are theories which support a pre-renal or renal cause. From our experience, we postulate that the mechanism of ARF in our case could be secondary to acute tubular necrosis (ATN). The clinical euvolemia status with the absence

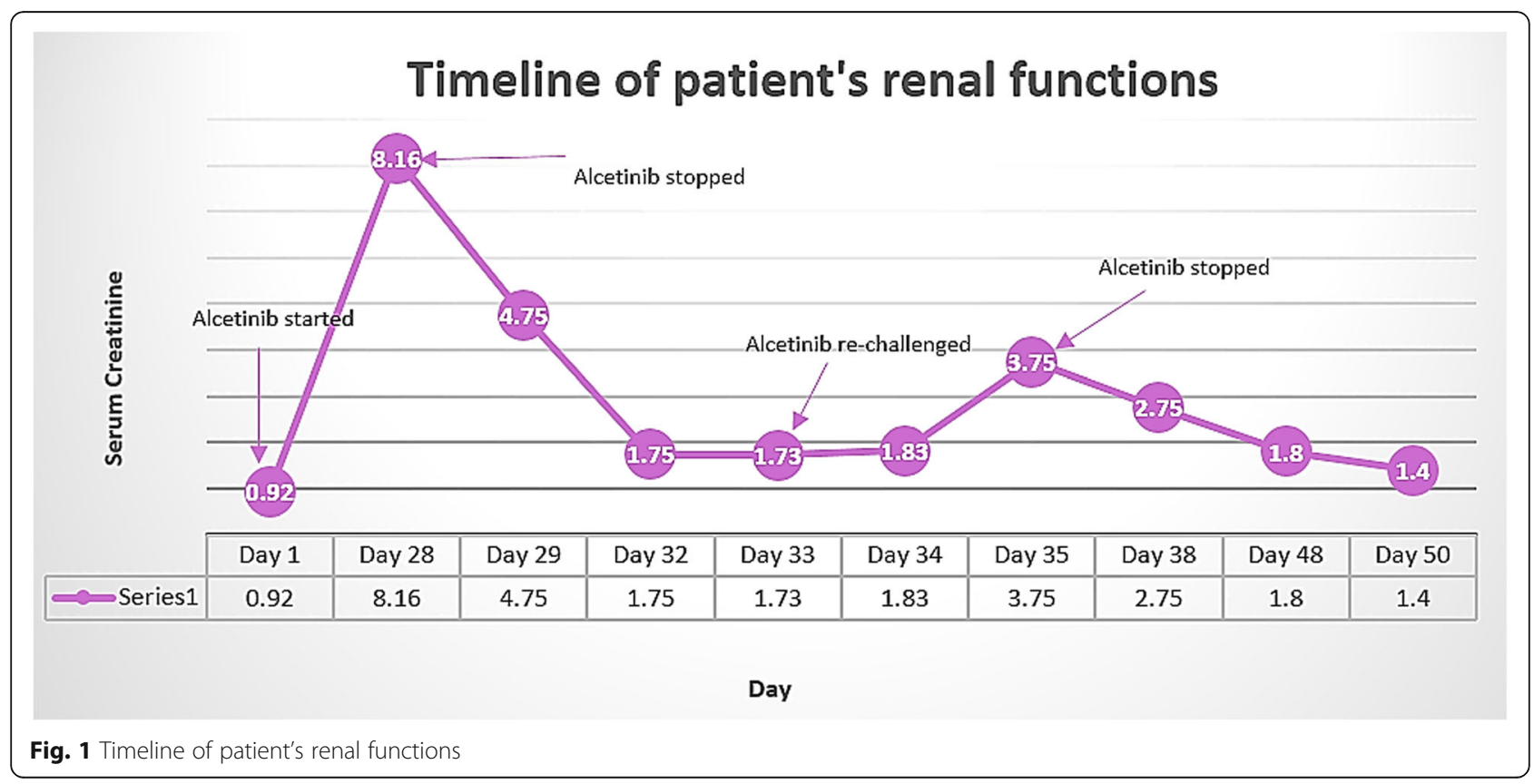


of any underlying heart failure and lack of exposure to any nephrotoxic agents supported the diagnosis of ATN. The laboratory evidence of ATN included BUN/Cr ratio of 13 , high FENa of $16 \%$ on presentation, urine sodium $>83 \mathrm{mEq} / \mathrm{L}$, urinary osmolality of $<350 \mathrm{mOsm} /$ $\mathrm{kg}$, and no evidence of obstruction (hydronephrosis) on renal imaging.

While renal biopsy would be helpful in distinguishing among various renal pathologic entities (that is, glomerular versus tubulointerstitial disease versus thrombotic microangiopathy), it would not prove definitive cause and effect. The temporal relationship between the initiation of therapy with this drug and the development of renal dysfunction, as well as the absence of other causes of acute kidney injury (AKI), is supportive of the association of alectinib with the episode of renal failure.

It is interesting to note that alectinib which is excreted mostly by hepatobiliary route (98\%) can still cause nephrotoxicity, despite the hepatobiliary route of metabolism. Due to the high renal blood flow to the kidney, exposure of tubular cells to the drug can be significant. Also, despite the low filtration of the given drug, luminal concentrations of the medication can be quite high due to fluid reabsorption throughout the tubule.

Nephrotoxicity associated with alectinib can be reduced by discontinuing the medication and re-challenging with a reduced dose to avoid dose-related nephrotoxicity [9]. The other measures which could reduce this complication would be to avoid volume depletion and dehydration in addition to avoiding the concomitant use of other nephrotoxic medications. Investigating further for other causes of renal failure would narrow down the differentials. Frequent monitoring of renal functions by trending $\mathrm{Cr}$ levels before initiating therapy and periodically every week would help to identify the patients at high risk of renal dysfunction. These patients could be followed up monthly if their Cr levels remained stable. Early nephrology referral is considered helpful to reduce the mortality and the hospitalizations in these patients.

\section{Conclusions}

Our patient's case demonstrates an extremely rare side effect of alectinib. Alectinib-induced nephrotoxicity has so far been reported in $<4 \%$ of patients in research studies [9]. Median time to cause grade III-IV renal impairment was around 4 months. In contrast, our patient developed grade IV renal impairment ( $\mathrm{Cr}>6$, upper limit of normal) within 6 weeks of starting the treatment and required emergency dialysis. ATN seems to be the most common underlying mechanism of alectinib-induced nephrotoxicity. It was found to be completely reversible when the inciting medication was discontinued. Although renal toxicity is not a common side effect, this case emphasizes consideration of alectinib-induced nephrotoxicity as an underlying reason for azotemia during alectinib therapy.

\section{Availability of data and materials}

Data sharing is not applicable to this article, because no datasets were generated or analyzed during the current study.

\section{Authors' contributions}

PR wrote the manuscript. JW supervised the writing of the manuscript. The other coauthors collected the data and discussed the content of the

manuscript. All authors read and approved the final manuscript.

Ethics Approval and consent to participate

Not applicable.

\section{Consent for publication}

Written informed consent was obtained from the patient for publication of this case report and any accompanying images. A copy of the written consent is available for review by the Editor-in-Chief of this journal.

\section{Competing interests}

The authors declare that they have no competing interests.

\section{Publisher's Note}

Springer Nature remains neutral with regard to jurisdictional claims in published maps and institutional affiliations.

\section{Author details}

${ }^{1}$ Division of Hematology/Oncology, Brookdale University Hospital Medical Center, Brooklyn, NY 11212, USA. ²Division of Nephrology, New York Presbyterian Queens, Flushing, NY, USA.

Received: 15 June 2018 Accepted: 13 September 2018

Published online: 19 October 2018

\section{References}

1. Soda M, Choi YL, Enomoto M, Takada S, Yamashita Y, Ishikawa S, Fujiwara SI, Watanabe H, Kurashina K, Hatanaka $\mathrm{H}$. Identification of the transforming EML4-ALK fusion gene in non-small-cell lung cancer. Nature. 2007:448:561.

2. Kinoshita K, Asoh K, Furuichi N, Ito T, Kawada H, Hara S, Ohwada J, Miyagi T, Kobayashi T, Takanashi K, et al. Design and synthesis of a highly selective, orally active and potent anaplastic lymphoma kinase inhibitor (CH5424802). Bioorg Med Chem. 2012;20:1271-80.

3. Peters S, Camidge DR, Shaw AT, Gadgeel S, Ahn JS, Kim D-W, Ou S-HI, Pérol M, Dziadziuszko R, Rosell R. Alectinib versus crizotinib in untreated ALKpositive non-small-cell lung cancer. N Engl J Med. 2017;377:829-38.

4. Gilbert JA. Alectinib surpasses crizotinib for untreated ALK-positive NSCLC. Lancet Oncol. 2017;18:e377. https://doi.org/10.1016/S1470-2045(17)30482-5.

5. Seto T, Kiura K, Nishio M, Nakagawa K, Maemondo M, Inoue A, Hida T, Yamamoto N, Yoshioka H, Harada M. CH5424802 (RO5424802) for patients with ALK-rearranged advanced non-small-cell lung cancer (AF-001.JP study): a single-arm, open-label, phase 1-2 study. The Lancet Oncology. 2013;14:590-8.

6. Tran PN, Klempner SJ. Focus on Alectinib and Competitor Compounds for Second-Line Therapy in ALK-Rearranged NSCLC. Front Med (Lausanne). 2016;3:65.

7. Yang JC, Ou SI, De Petris L, Gadgeel S, Gandhi L, Kim DW, Barlesi F, Govindan R, Dingemans AC, Crino L, et al. Pooled Systemic Efficacy and Safety Data from the Pivotal Phase II Studies (NP28673 and NP28761) of Alectinib in ALK-positive Non-Small Cell Lung Cancer. J Thorac Oncol. 2017; 12:1552-60.

8. Gadgeel SM, Gandhi L, Riely GJ, Chiappori AA, West HL, Azada MC, Morcos PN, Lee RM, Garcia L, Yu L, et al. Safety and activity of alectinib against systemic disease and brain metastases in patients with crizotinib-resistant ALK-rearranged non-small-cell lung cancer (AF-002JG): results from the dose-finding portion of a phase 1/2 study. Lancet Oncol. 2014;15:1119-28.

9. Shimada M, Fukuda M, Fukuda M, Kitazaki T, Hashiguchi K, Ikeda T, Yamaguchi H, Nakatomi K, Ashizawa K, Mukae H. Adverse renal effects of anaplastic lymphoma kinase inhibitors and the response to alectinib of an ALK+ lung cancer patient with renal dysfunction. Onco Targets Ther. 2017; 10:3211-4. 